\title{
Overcoming Obstacles to Evolution Education: The OOPSIE Compromise-A Big Mistake
}

\author{
Eugenie C. Scott • Glenn Branch
}

Published online: 15 February 2008

C) Springer Science + Business Media, LLC 2008

\begin{abstract}
Opt-out policies are typically invoked to excuse students from activities to which they or their parents may have religious objections, such as reciting the Pledge of Allegiance, dissecting animals in a laboratory, or attending sex education classes. Occasionally, however, a school or school district allows students to opt out of academic topics, including, sometimes, evolution. Opt-out policies specifically including evolution are a big mistake-for the students who opt out, for their classmates whose studies are disrupted, and especially for their teachers, who cannot fulfill their duty to instruct their charges about biology without emphasizing evolution.
\end{abstract}

Keywords Evolution education · Opt-out policies ·

Hatch Amendment . Grassley Amendment .

Protection of Pupil Rights Amendment .

Theodosius Dobzhansky

"Dear NCSE, I have a student whose father wants me to let his son opt out of instruction in evolution this semester. The principal says, 'let him do genetics'. I can't have the kid do Punnett squares for four weeks! What can I do?"

"Dear NCSE, a member of our school board claims that something called the 'Hatch Amendment' requires our teachers to let students opt out of instruction in evolution. Can this possibly be true?"

E. C. Scott $(\bowtie) \cdot$ G. Branch

National Center for Science Education,

P.O. Box 9477, Berkeley, CA 94709-0477, USA

e-mail: scott@ncseweb.org
"Dear NCSE, We don't have a controversial issues policy in my district, so do I have to let a student who says that learning evolution is against her religion opt out of learning about evolution?"

Here at the National Center for Science Education, we receive a steady stream of questions from parents, teachers, science supervisors, and school board members about whether to allow students to opt out of instruction in evolution. Such policies complicate science instruction, of course, and (as we argue below) they have a bad effect on the students who opt out, on their classmates whose studies are disrupted, and especially on their teachers, who cannot fulfill their duty to instruct their charges about biology without emphasizing evolution. Particularly, in communities in which creationism is prevalent, allowing students to opt out is often viewed as a satisfactory compromise whereby evolution is taught in general but not inflicted on the unwilling. But is it really satisfactory?

As we use the term, opt-out policies (OOPs) are policies that allow students to be withdrawn from activities at school that address topics that they or their parents consider to be offensive or otherwise inappropriate. Not included under the rubric is the practice of allowing students to choose their classes from a choice provided by the school, which might allow them to avoid offensive activities, or the practice of informally steering students who are (or whose parents are) suspected of harboring objections to certain activities to classes where they are minimized or avoided altogether, or the practice of allowing (or even encouraging) students to attend private rather than public schools to avoid activities that they or their parents deem offensive.

The sources of OOPs vary. Sometimes OOPs are mandated by state law. In California, for example, the law allows students in the public schools to opt out of sex 
education and to opt out of animal dissection when they have a moral objection to it ("ick!" is not enough). Sometimes, individual school districts or schools go beyond the demands (if any) of state law, adopting OOPs of their own, which may either be general (policies about "controversial issues" sometimes include OOPs) or refer to specific practices that are of especial concern in their communities. And sometimes, of course, students or their parents may request - or demand - permission to opt out of a particular activity, even in the absence of any formal OOP.

Few OOPs explicitly involve academic topics, but when they do, there is typically a provision that ensures that the students who are opted out will, if possible, have to engage in a substitute activity to acquire the knowledge or ability that the objectionable practice is supposed to impart. In the case of animal dissection, for example, a district may allow the use of detailed plastic models or interactive dissection software. The rationale for such provisions is both obvious and compelling: for basic academic topics, students simply need to learn the material, by hook or by crook.

Therefore, when it comes to OOPs specifically including evolution (OOPSIEs), the acronym illustrates our view: Because of the centrality of evolution to biology, such policies are a bad mistake. As Theodosius Dobzhansky famously wrote 25 years ago, "Nothing in biology makes sense except in the light of evolution" (Dobzhansky 1973). Evolution inextricably pervades the biological sciences; it therefore pervades, or at any rate ought to pervade, biology education at the $\mathrm{K}-12$ level. There simply is no alternative to learning about it; there is no substitute activity. A teacher who tries to present biology without mentioning evolution is like a director trying to produce Hamlet without casting the prince. By the same token (and to vary the play), a student who is opted out of evolution is likely to regard biology as a tale told by an idiot, full of sound and fury, signifying nothing.

Shakespeare aside, it is not only students who are opted out of evolution who suffer as a result of OOPSIEs. Accommodating such students is bound to be disruptive to the course as a whole; ironically, the better the treatment of evolution in the course, the worse the disruption. A student opting out of evolution in such a course would have to bob in and out of the classroom several times a month, disappearing, for example, when the structure of the cell is taught (and with it the endosymbiotic origin of mitochondria), and again when taxonomy is taught (and with it phylogenetic systematics), and yet again when genetics is taught (and with it molecular homology), and so on. It is simply unreasonable to expect a teacher to install a revolving door, as it were, to accommodate students who are unwilling to hear the dreaded e-word.

Moreover, OOPSIEs are bad for schools and districts. Students who fail to learn about evolution are not going to perform as well on statewide examinations, which reflects poorly not only on them but also on their schools and districts. Nor are they going to perform as well in their biology classes in colleges and universities, where the faculty expects incoming students to have at least a basic grasp of evolution. Indeed, high school administrators often have to certify that the courses intended to prepare students for college in fact do so; allowing students to opt out of topics that are central to such classes may result in decertification. Schools and districts with OOPSIEs may also find it difficult to attract and retain those science teachers who take their professional responsibilities seriously: given a choice, who would prefer to teach biology at a school where the administrators are unwilling to support the teaching of evolution?

Faced with a proposed or actual OOPSIE, what is a science teacher to do? School and district administrators need to be reminded that science teachers deserve to be treated as professionals, trained in both the content of science and the methods of education; as such, their professional opinions about the necessity of including evolution in the biology curriculum deserve to be heeded. In addition, of course, their professional groups, such as the National Science Teachers Association, unequivocally endorse "the position that evolution is a major unifying concept in science and should be included in the $\mathrm{K}-12$ science education frameworks and curricula....if evolution is not taught, students will not achieve the level of scientific literacy they need" (NSTA 2003). Administrators also need to be reminded of the practical repercussions of OOPSIEs: the burdens imposed on teachers, the disruptions caused to the educational process, the damages wreaked on the school's reputation.

Claims that OOPSIEs are required by the Constitution, federal law, or state law deserve skepticism. For example, the Protection of Pupil Rights Amendment (PPRA) - sometimes called the "Hatch Amendment" or the "Grassley Amendment"-is occasionally claimed to require school districts to allow students to opt out of various topics, including evolution. In fact, the PPRA is limited in scope, applying only to surveys, analyses, and evaluations funded by the federal Department of Education, and is intended only to protect the privacy of parents and students with regard to such studies; it neither sets limits on the school district's control over its curriculum nor provides any right for students to be opted out from regular classes (Simpson 1996). However, boilerplate citing the PPRA continues to circulate, dismayingly.

In dealing with individual parents who are requestingor demanding - permission for their children to be opted out of instruction in evolution, not necessarily seeking the institution of a formal OOPSIE, different strategies are appropriate. Such parents are generally going to be conservative Christians who are worried, at bottom, about 
the prospect that instruction in evolution will challenge or damage their children's faith and that their children will be forced to "believe" in evolution. What helps to alleviate their concern is not a defensive citation of the importance of evolution in the curriculum or the practical repercussions for the school, but a respectful engagement with their worry.

According to teachers on the front lines, it helps to reassure such parents that the aim of education is to impart understanding, not to compel belief. As Ella Ingram and Craig Nelson (2006: 20) put it, "we believe that understanding evolution is more important than accepting evolution, and indeed that, ethically, we should ask students to strive for understanding prior to making decisions regarding acceptance of any theory." Students are asked only to understand evolution and appreciate its evidential basis - not to profess a faith in evolution, much less to renounce their religious views. Indeed, even the major creationist organizations agree that students ought to learn about evolution, although they themselves misunderstand and misrepresent it.

It helps also to explain that there is a range of attitudes about evolution and religion. Although there are those who regard evolution as incompatible with or even threatening to their faith, there are also those who regard it as compatible with or even enriching their faith. Among the latter, cited in the new publication Science, Evolution, and Creationism (NAS 2008), are not only religious leaders like the late Pope John Paul II but also prominent scientists like Francis Collins and Kenneth R. Miller, both of whom have written eloquently on evolution and their faith (Collins 2006; Miller 2007). Not all parents will share the religious views of such authors, of course, but they may be impressed enough by their sincere devotion to heed their insistence that, to understand modern science, a student needs to learn about evolution.

Ultimately, parents and teachers want the same things: for their children and students to do well in school, learn the subject material, and become educated citizens. Accomplishing these goals requires that teachers ensure the competence of students in basic subjects such as biology, to which evolution is central. That is why OOPSIEs are not a satisfactory compromise but just a big mistake.

Acknowledgments We thank the members of NCSE's legal advisory committee, especially Ehrich Koch, for their guidance; they are of course not responsible for the views expressed here. We blame our colleague Joshua Rosenau for the reference to the Scottish play.

\section{References}

Collins FS. The language of God: a scientist presents evidence for belief. New York: Free Press; 2006.

Dobzhansky T. Nothing in biology makes sense except in the light of evolution. Am Biol Teach. 1973;25:125-9.

Ingram EL, Nelson CE. Relationship between achievement and students' acceptance of evolution or creation in an upper-level evolution course. J Res Sci Teach. 2006;43(1):7-24.

Miller KR. Finding Darwin's God: a scientist's search for common ground between God and evolution. New York: Harper Perennial; 2007.

[NAS] National Academy of Sciences. Science, Evolution, and Creationism. Washington DC: National Academies Press; 2008. Available at: http://www.nap.edu/sec (accessed January 11, 2008).

National Science Teachers Association (NSTA). Position Statement: The Teaching of Evolution. 2003. Available at: http://www.nsta. org/about/positions/evolution.aspx (accessed January 11, 2008).

Simpson MD. What's a teacher to do? NEA Today. 1996;14(6):25. Available at: http://findarticles.com/p/articles/mi_qa3617/ is_199602/ai_n8750005 (accessed January 11, 2008). 